\title{
ANTROPOLOGÍA
}

\section{UN CURIOSO MANUSCRITO ETNOGRÁFICO}

\author{
Santiago Díaz Piedrahita*
}

\begin{abstract}
RESUMEN
Díaz Piedrahita S.: Un curioso manuscrito etnográfico. Rev. Acad. Colomb. Cienc. 37 (143): 159-176, 2013. ISSN 0370-3908.

Se transcribe y comenta un manuscrito titulado Antigüedades indígenas y que incluye un Diccionario Etnológico de Colombia, obra de autor desconocido y que contiene información a sobre once tribus o grupos a saber: Caberres, Caribes, Chocoes, Caparras, Catíos, Culimas, Coconucos, Chiricoas, Conchas, Correguajes y Cunas. El texto además incluye unas notas tituladas: Apuntes sobre la lengua Caribe, tomados por un antiguo misionero del Orinoco cuyo nombre se ignora por haberse perdido las primeras páginas del importante manuscrito de que estas fojas hacian parte. Por sus características, estos textos fueron redactados en el siglo XIX y hacían parte de una obra mayor.
\end{abstract}

Palabras clave: Etnografía, antropología, Colombia.

\begin{abstract}
The manuscript entitled Indian Antiques, which includes an anonymous Ethnological Dictionary of Colombia, is transcribed and commented. The text contains information about eleven tribes or indigenous groups known as: Caberres, Caribes, Chocoes, Caparras, Catios, Culimas, Coconucos, Chiricoas, Conchas, Correguajes and Cunas. It also includes some notes entitled: Annotations on Caribbean Language, written by a former missionary of the Orinoco whose name remains unknown, as the first few pages of this important manuscript are missing. Due to its characteristics, these texts were written in the nineteenth century.
\end{abstract}

Key words: Ethnography, anthropology, Colombia.

\section{Introducción}

En la Biblioteca de la Provincia Franciscana de la Santa Fe de Colombia, concretamente en el Convento de San Francisco en Bogotá se conserva un pequeño librito manuscrito titulado Diccionario Etnológico de Colombia. Esta obra consta de varios fascículos reunidos en un cuadernillo de cerca de $17 \mathrm{~cm}$. de largo por $11 \mathrm{~cm}$. de ancho, con 93 folios, algunos en blanco. Tal cuadernillo no es homogéneo en su configuración, pues fue conformado al unir varias libretas, cada una numerada a partir de su primera página. Aparentemente se trataba de una obra de mayor envergadura en la que se tratarían todas las etnias residentes en el territorio colombiano. Esto parece indicar el título, el cual implica una presentación ordenada de temas relativos a una materia determinada. Infortunadamente los cuadernillos que se conservan y que se trascriben en el presente texto corresponden únicamente a las letras $\mathbf{C}$ y $\mathbf{C H}$ (hoy incorporada a la $\mathrm{C}$ en

\footnotetext{
* $\quad$ Académico de número.
} 
el alfabeto español), faltando las notas correspondientes a las demás letras. La grafía y el papel, en las distintas libretas, son similares, exceptuando unos folios, escritos en papel de otra calidad y con una grafía más antigua. Este fascículo titulado: Antigüedades Indígenas lleva una portadilla redactada por el autor del resto de la obra y que señala que tal fragmento corresponde a unos: Apuntes sobre la lengua Caribe, tomados por un antiguo misionero del Orinoco cuyo nombre se ignora por haberse perdido las primeras páginas del importante manuscrito de que estas fojas hacían parte. El autor de este cuadernillo parece corresponder a las iniciales M. D. M., que figuran al inicio de la segunda página. Con excepción de este pequeño fragmento, las demás libretas debieron ser redactadas por una misma persona, pues corresponden a mismo estilo y a una misma grafía. El autor del Diccionario Etnológico de Colombia, cuyas iniciales son $\mathbf{L}$. M. J., pudo ser un humilde fraile misionero, pero la lectura del texto indica que el autor debió ser un fraile estudioso y conocedor de la etnología colombiana cuyo propósito era el de redactar una obra general de mayor aliento organizada alfabéticamente para conformar su diccionario. Lamentablemente, de este trabajo sólo se conservan los apartes que cubren, en su orden, lo relativo a los indios Caberres, Caribes, Chocoes, Caparras, Catíos, Culimas, Coconucos, Chiricoas, Conchas, Correguajes y Cunas.

El contenido de cada una de las doce libretas que se conservan aparece perfectamente ordenado e incluye la información pertinente a un grupo o nación; cada cuadernillo lleva una numeración consecutiva y el texto carece de enmiendas, circunstancia que sugiere se trate de una versión final, a la que el autor hizo algunas adiciones a manera de notas aclaratorias. Por ello pensamos que era su objetivo elaborar una obra general, como lo sugiere el título. En un acápite del texto el fraile etnólogo menciona un Atlas Etnográfico de Colombia. Allí dice textualmente: "En la P. 2 de nuestro Atlas" se encuentra publicado un diseño del tipo de los coconucos". Desafortunadamente, esta obra, en la que fueron ilustrados los indígenas tratados en el texto permanece refundida. En otro fascículo le da el nombre de Galería Etnológica.

Lo que se conserva de la obra dejan abierta la posibilidad de que el autor fuese un verdadero conocedor de los temas etnológicos, interés que le habría surgido durante el desempeño de su labor misionera, tiempo en el cual habría recopilado la información pertinente a algunos grupos, información que enriqueció y complementó utilizando otras fuentes. Este fraile etnógrafo debió redactar su obra durante la segunda mitad del siglo XIX. Esta hipótesis se desprende, tanto del tipo de

* Infortunadamente este Atlas, donde están ilustrados los indígenas tratados, permanece refundido. papel de los cuadernos como del estilo de letra utilizado, de las normas ortográficas vigentes en la época y especialmente de algunos autores de ese periodo a quienes se menciona en el texto. Entre los personajes citados cabe nombrar al coronel Agustín Codazzi cuya obra es comentada, aparte de que el autor manifiesta haber observado en la Biblioteca Nacional de Bogotá las láminas elaboradas por los pintores de la Comisión Corográfica. Nuestro etnólogo también consultó la Geografía de los Estados Unidos de Colombia del general Tomás Cipriano de Mosquera, la Historia de la Literatura en Nueva Granada de José María Vergara y Vergara, de quien también menciona Los indios de Andaquí y Memorias de un viajero, obra conjunta de Vergara y de Evaristo Delgado. Cita también otros autores de ese periodo como el médico y botánico bogotano Francisco Bayón Fernández, el viajero Charles Saffray, el reconocido botánico Alphonse De Candolle y el arqueólogo ingles John Lubbock, autor de El Origen de la civilización y la condición primitiva del Hombre, uno de los mayores difusores de las teorías antropológicas promulgadas entonces. Igualmente alude a Carlos Calvo y a Fernando Cardín. Además de estos autores, propios del la segunda mitad del siglo XIX, nuestro personaje menciona el Diario de Cristóbal Colón, cita a algunos cronistas de Indias como José Gumilla, autor del Orinoco Ilustrado, Lucas Fernández de Piedrahíta, autor de las Elegías de varones Ilustres de Indias y Pedro Cieza de León, autor de la Crónica del Perú. También nombra a Antonio de Herrera y Tordecillas, autor de la Historia General de los hechos de los castellanos en las Islas de Tierra Firme del Mar Océano, obra más conocida como las Décadas y al naturalista alemán Georg Marcgraff, autor de Historia Naturalis Brasiliae. Menciona

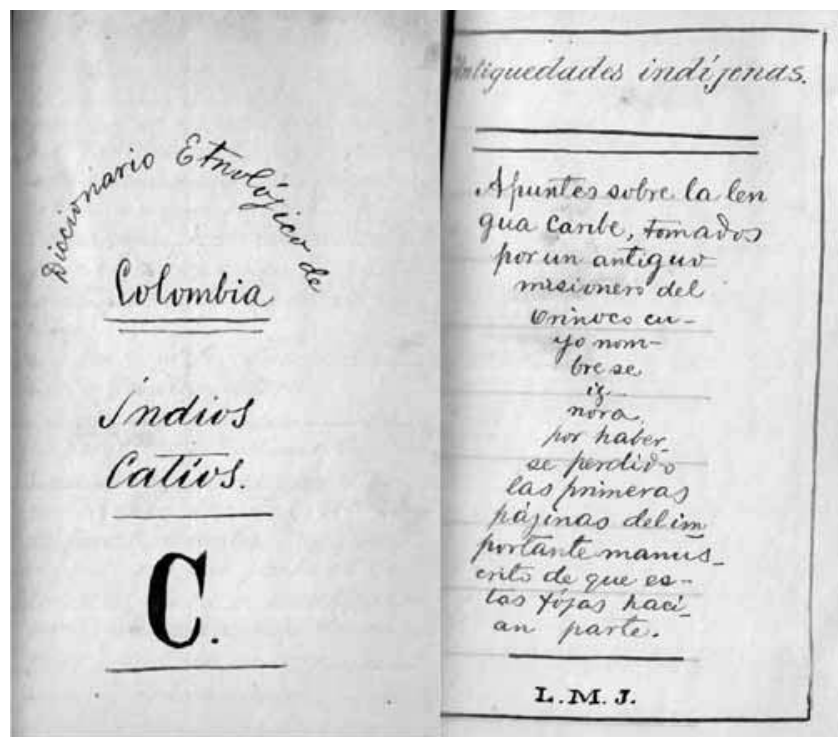

Portadillas de dos de los cuadernillos del Diccionario Etnológico de Colombia. 
también a Alcedo y a Alejandro de Humboldt y se refiere a otros trabajos como History of the Caribby Islands y Travel in South America.

Se trata de una persona culta y erudita por haber leído mucho, que conoce los clásicos griegos entre quienes menciona a Plinio el Viejo y a Porfirio, así como a Estrabon el gran geógrafo de la Grecia Antigua.

Los notas de pie de página marcadas con asterisco $(*)$ corresponden a notas incluidas por el etnólogo. Las distinguidas con una numeración seriada corresponden a observaciones del transcriptor.

\section{Diccionario etnológico de Colombia** Indios Caberres}

\section{C}

\section{Indios Caberres.}

Los Caberres, habitadores de las márgenes del Orinoco a 400 leguas de su desembocadura y algunos de sus afluentes, usan por gala muchas sartas de dientes y muelas de gente, para expresar por ellas, que esos son los despojos de los enemigos que han matado.

Usan comunmente estos adornos, la flauta o fatuto y la macana, cada cual con sus borlas, para sus faenas y viajes ordinarios; pero en sus fiestas de casamientos o cumpleaños de sus caciques, se pintan con diversos colores preparados en combinación con la resina caraña**, y se forman en todo el cuerpo hermosos y complicados dibujos que de lejos presentan un vistoso aspecto, y asemejan vestidos de punto, bien matizados; los músicos, además de sus pinturas, se adhieren por medio de la resina, plumas de hermosos colores, y se ponen diademas de plumajes, con lo cual presentan el más singular aspecto.

Estos plumajes de la cabeza los usan también mientras navegan y cuando trabajan en las faenas del campo, pues los protege contra los ardores del sol.

Las mujeres usan además largas sartas de cuentecillas que labran de caracoles primorosamente, y que llaman quiripa, sartas de dientes de mono y otros animales, y en cada oreja se atraviesan un gran colmillo de caimán; las mujeres se aprietan desde que nacen, con fuertes cordeles de pita, hacia arriba de los tobillos, y abajo de las rodillas, con lo cual lo-

** En la trascripción, y para facilidad de los lectores, se ha modificado la ortografía de acuerdo con las normas actuales.

*** La caraña es una resina extraída de árboles de la familia Burseraceae, casi siempre de Bursera simaruba. gran que las pantorrillas engrosen notablemente, lo cual es entre estos indios hermosura.

Copiosa es en pueblos y gentes esta nación, y sobrepuja a muchas en valor y ferocidad; contra ellos se estrellaban las armadas Caribes; pues son brutales en su venganza; buscan y persiguen a sus enemigos para devorarlos, pero cuando están de paz, son tratables y complacientes.

Pueblan el Orinoco y su región occidental hasta la boca del Ariari, sosteniendo en el Guaviare sus sangrientas guerras con los formidables Caribes.

Preparan el color rojo, mejor que todos los otros pueblos salvajes, pues solo los igualan en ello los Guasipunabis.

$$
\text { - Población y guerras - }
$$

La nación Caberre, aun más carnicera y bárbara que la Caribe, es tan numerosa, que hace frente a las invasiones de los Caribes, que suben, ya con 80 ya con 100 piraguas de guerra a invadirlos, pero que siempre han llevado el peor partido, porque aunque procuran tomar por asalto, con mil precauciones sus colonias, los Caberres se juntan y los rechazan, pues inmediatamente tiene el aviso que les dan los centinelas o atalayas que siempre mantienen en las lomas más altas de su territorio, desde donde se domina gran parte del Orinoco, provistos de grandes y retumbantes tambores, en los cuales tocan su llamada a las armas, y bien pronto este llamamiento, transmitido de pueblo en pueblo, se hace general, saliendo de sus casas los numerosos y valientes caberres a combatir o esperar a pecho descubierto al enemigo, que al verse descubierto, para a respetable distancia, y sigue a llevar su exterminio a otras menos belicosas naciones.

Sus grandes tambores consisten en un tronco hueco de árbol bastante grueso, de modo que a veces ni dos hombres pueden abarcar, con el espesor de un dedo, y de unas tres varas de largo. Las dos extremidades quedan abiertas, lo cual logran a fuerza de fuego, apagándolo con agua cada vez que es necesario. En la parte superior les hacen sus claraboyas, al modo de las del arpa y en medio le forman una media luna, como una boca, por donde la repercusión sale con más fuerza; y abajo, en el centro de la caja, en sitio perpendicularmente correspondiente a la media luna, hay fijada con el betún peraman, ${ }^{*}$ una piedra de unas dos libras de peso $^{* * * *}$; luego tapan las dos bocas extremas; golpean con mazos envueltos en una

* Especie de lacre fabricado con cera negra y otras resinas derretidas, que sirve para curar las fracturas y así la usan también los indios.

**** El peramán corresponde a Simphonia globulifera L.f., planta de la familia Clusiaceae, tradicionalmente utilizada por los indígenas de la cuenca del Orinoco como medicinal, especialmente para las cefalalgias y también para calafatear. 
resina, currucay, sobre la media luna del medio, con lo cual suenan tan estrepitosamente como ya dijimos; pero no debe esta formidable caja tocar con el suelo, sino que la cuelgan con dos bejucos de a cuatro o seis brazadas de un palo horizontal suspendido de dos estacas.

Este tambor cuyo sonido tanto se pondera, es invención caberre, según dicen los indios y así parece, pues aunque otras tribus también lo usan, nunca lo fabrican tan bien como estos.

En valor solamente los Otomacos imitan algo a los Caberres, pues aunque los Caribes tienen fama de ser muy valientes, más puede en ellos la astucia, el número y la traición, que otra cosa, pues de suyo son muy temerosos y cobardes.

Es solamente entre los indios caberres, en la región del Orinoco, donde se fabrica el mortal veneno curare $^{* * * * *}$ que mata instantáneamente al inocularse en la sangre porque la coagula o hiela en pocos segundos. Ellos guardan el secreto, y sólo lo venden una vez fabricado y guardado en botecillos de barro nuevos que contienen unas cuatro onzas. Vienen o mandan de todas las demás naciones del Orinoco a comprarles este mortal veneno que guardan como bálsamo precioso, del cual se sirven en sus cacerías de toda clase de fieras, sin que ello impida comer la carne de la bestia envenenada, pues el efecto no lo produce este veneno por las vías digestivas.

El curare ha sido ensayado con buen éxito contra las convulsiones, la coréa, el histérico [y] la epilepsia.

Datos sobre el Curare.

"Este es el Rouhamon Curare de De Candolle y de la familia de las Loganiaceas, cuyos caracteres sacados del texto latino son los siguientes":

"R. Curare, fruticosum scandens, ramis fuscescenti tomentosis, foliis ovato - oblongis acuminatis reticulato triplinervis glabris, ciliatis petiolo nervoque medio fuscenti - tomentosis."

Arbusto tortuoso de ramas sarmentosas cubiertas de pelos extendidos, largos y aleonados; de hojas sentadas oval oblongas, agusadas, membranosas, trinerviadas, aleonado peli erizadas, por ambas caras con pelo largo, y largas de 3 a 4 pulgadas; bayas, flores color de fuego con baya globosa, lampiña del tamaño de una manzana regular, con 10 a 20

***** El curare es por lo general una mezcla de zumos de varias plantas e incluso de exudados de algunos animales, especialmente ranas, empleado como veneno de flechas y virotes. El principal ingrediente se extrae de varias especies de bejucos del género Strichnos de la familia Loganiaceae. semillas oblicuamente arriñonadas, discoideas y anchas de una pulgada.

"La preparación del curare es muy sencilla, dice el señor de Humboldt; la planta o bejuco de que se saca esta sustancia se cría con abundancia en las serranías que hay entre los ríos Tepete y Majagua; importa poco que el macavure (curare) sea fresco, o que haga algunas semanas que se le haya cogido; en la corteza y en la parte correspondiente de la albura, es donde está el veneno. Rállanse con un cuchillo las ramas de Macavure (curare) de 4 o 5 líneas de diámetro, muélense las ralladuras hasta volverlo hebras muy finas, y siendo el zumo amarillo, comunica ese color a la maza (sic). Se vierte en una vasija, se deslíe en agua fría y luego se filtra por medio de una alquitara; el líquido que pasa gota a gota, tiene un color amarillento, que se concentra por evaporación y adquiere luego un sabor muy amargoso; entonces es preciso darle cuerpo o hacerlo pegajoso, lo que se consigue mezclándole un sustancia glutinosa".

Como su acción ataca a los nervios de la vida animal, paraliza los músculos de la respiración y produce la muerte por asfixia, mientras que no interesa de manera alguna a los de la sensibilidad." (Bayón) ${ }^{* * * * * *}$

Dice el padre Gumilla, que este veneno lo extraen de una raíz de color pardo, del mismo nombre, que se desarrolla entre los pantanos y aguas estancadas, la cual sacan los caberres, y después de lavada y machacada la ponen a hervir en grandes ollas a fuego lento, y para tal faena mandan a la india más vieja de su tribu a rebullir las ollas, y si cae muerta por la continua respiración de los vapores del curare, mandan otra vieja a reemplazarla, sin que esto sea extraño, pues bien saben todos que es ese el destino y fin de las viejas; cuando el cocimiento toma un color de arrope* claro, y se disminuye en una tercera parte, condensado ya, avisa la vieja que está fabricado y entonces acude el cacique con los capitanes y demás gente a examinar el veneno; para esto, moja en él la punta de una flecha y la pone a cierta distancia de una heridita que se hace alguno de los concurrentes; si la sangre se detiene al salir, es porque ya está el veneno a punto.

Mucha es la duración que tiene aun estando seco en las flechas, pues no pierde en muchos años su vigor y basta mojar con agua o saliva la flecha, para que este suba de punto, y el efecto sea más rápido.

Los Caberres y Caribes usan por gala sartas de dientes y muelas humanas.

\footnotetext{
****** Alude a Francisco Bayón Fernández (18 - 1), médico y naturalista bogotano, la mayor autoridad en su tiempo en temas botánicos.

* Mosto cocido hasta la consistencia de miel.
} 


\section{Diccionario Etnológico de Colombia Indios Caribes}

\section{C}

\section{Indios Caribes}

La nación sobresaliente y dominante en Orinoco, dice Gumilla, es la nación Caribe, que se extiende por la costa oriental hasta la Cayana (sic.) ${ }^{* * * * * * *}$, y aun hoy vive mucha gente de ellos en la Trinidad de Barlovento, y las tres islas de Colorados, que están junto a la Martinica; ni se que haya en aquellos países nación que le iguale en extensión y gentío, si ya no es, que después de descubierta enteramente la de los Caberres, la iguale o exceda.*

Son los Caribes de buen arte, altos de cuerpo y bien hechos; hablan desde la primera vez con cualquiera, con tanto desembarazo y satisfacción, como si fuera muy amigo y conocido. En materia de ardides y traiciones son maestros aventajados, por lo mismo que de suyo son muy temerosos y cobardes. Preguntados estos, de donde salieron sus mayores? no saben dar otra respuesta, que esta: Ana cariná róte, esto es: Nosotros solamente somos gente. Esta respuesta nace de la soberbia con que miran al resto de aquellas naciones, como esclavos suyos; y con la misma lisura se lo dicen en su cara con estas formales palabras: Amucón paporóro intóto nantó: todas las demás gentes son esclavos nuestros. Esta es la altivez bárbara de esta nación cariba; y realmente trata con desprecio y con tiranía a todas aquellas gentes, rendidas unas, y otras temerosas de su yugo.

Los caribes castigan con la muerte el adulterio, cosa rara entre las naciones del Orinoco, que poco alto hacen en este delito, pues algunas llevan su compción $(?)^{* * * * * * * *}$ hasta tener establecido el cambio de mujeres por tiempo convencional entre los contratantes.

En cambio usan la poligamia y Gumilla habla del jefe Jaguarica, que tuvo 30 mujeres, cada una de nación diferente.* Estas mujeres eran robadas a los pueblos vecinos, costumbre muy practicada por estos salvajes; y es fama que tenían tan pocas comunicaciones con ellas, que los hombres hablaban el caribe, y las mujeres sus respectivas lenguas maternas. El origen del matrimonio, después del comunismo de mujeres que sin duda existió en los primitivos tiempos, fue independientemente de toda consideración sagrada o social, el afecto mutuo o la simpatía; no tuvieron que ver en ello un consentimiento mutuo era inútil, y el matrimonio consistía, no en demostraciones amorosas por un lado, un tierno dévouement $^{* * * * * * * *}$ por otro, sino en violencia brutal y en sumisión forzada.**

Es notable el descuido con que los caribes crían a sus hijos, pues de chicos los idolatran, y al crecer los abandonan y no los reprenden por temor de que al ser hombres los maten.

Entre los caribes, cuando alguno de sus capitanes muere, acostumbran colgarle acostado en una hamaca de algodón que suspenden de las dos puntas, y allí permanecen cerca de treinta días sus mujeres o concubinas remudándose para custodiarle sin cesar, no obstante el mal olor que desde el segundo día comienza a desprender el cadáver al entrar en putrefacción, particularmente en los climas cálidos de sus dominios; ellas no permiten que mosca ni insecto alguno se pose sobre el cuerpo de su señor, y al llegarse el día del entierro, los hijos y parientes del difunto, después de ponerle a un lado en la sepultura su arco, flechas, macana rodela y demás armas, le tienden al otro lado una de esas sus mujeres para que en la otra vida le cuide y acompañe, para lo cual encogen regularmente a la más anciana, o a la madre del hijo mayor al cual tocan en herencia las demás mujeres. $\mathrm{Al}$ año sacan los restos, y encerrados en una caja, los cuelgan de los techos de sus casas para perpetua memoria.

Entre los caribes, como entre los otomacos, giraras, aincos y sálibas, abundan mucho los indios altos, corpulentos y bien proporcionados.

Los caribes llaman a Dios o el Espíritu Superior, Quiyumocón, es decir nuestro padre grande, pero según hace notar el P. Gumilla, no está bien averiguado si esta voz tiene por objeto la causa primera o si se refiere al más antiguo de sus abolengos.

La numerosa nación caribe dividida en varias parcialidades que hablan el mismo idioma, podía poner, según nos dice Gumilla, en su tiempo, hasta 12.000 indios sobre las armas en las regiones del Orinoco y costa venezolana marítima de barlovento.

\footnotetext{
******** Alude a la abnegación.

** Véase Lubock. O. de la Civilz., p 96. Esta nota aparece en los folios r y v. (La grafía correcta es Lubbock. y el título de la obra citada es: El Origen de la civilización y la condición primitiva del Hombre.)
}

******* Se refiere a Cayena, capital de la Guayana Francesa.

* $\quad$ Alcedo dice que las márgenes del Vichada estaban pobladas de caribes, entre los cuales fundaron misiones los jesuitas en el siglo XVII, pero estos salvajes las destruyeron y mataron a varios padres.

******** Quizá es una forma castellanizada de compecco, pecar con. 
En sus matrimonios poco cuidado ponen en que sus mujeres sean o no parientas cercanas, escrúpulo que tienen otras parcialidades y especialmente la de los Betoyes.

Opina el P. Gumilla que de las islas de Barlovento se trasportaron los caribes a la tierra firme de Paria, Santa Marta, Cabo de Vela a toda la costa actual de Venezuela y al Orinoco, en donde hoy se les encuentra en número considerable y lo mismo dice Alcedo. Aquellas islas se llamaron Caribales por que eran Caribes gran parte de los que las poblaban, y aun se conservan en algunas de ellas estos crueles salvajes, a quienes decretaron los reyes Fernando* e Isabel que por su barbaridad se les tratase como a esclavos. Apoya esta opinión la mucha afición que aun tienen como antiguo isleños a la continua navegación; se lanzan con increíble destreza, en piraguas rasas, hasta perder en el mar de vista la costa, llegan a la Martinica y otras islas de barlovento, y vuelven a la tierra firme sin riesgo de ahogarse; y si alguna oleada de tempestad les vuelve la piragua, hacen lo que Colón notó en su Diario; la ponen otra vez flotante, pues con los pies nadan y con las manos la enderezan.

Hoy han quedado, dice Alcedo, muy pocos que viven en tal cual isla, y la mayor parte en la Dominica que poseen enteramente.

Adoran un hombre que dicen fue increado y el primero de todos, que bajó del cielo, llamado Longuo, de cuyo ombligo nacieron algunos; y otros de una de sus piernas, que él mismo se abrió con un hierro; creen en la inmortalidad del alma $\mathrm{y}$ en un principio bueno y otro malo, y cuando muere alguno, entierran con él a sus esclavos y criados. Son polígamos, crueles y muy diestros en el manejo de las armas.

El citado autor dice también que esta nación está dividida en marítimos y mediterráneos; los primeros, que viven en las llanuras y costas del Atlántico, y los segundos, al sur del nacimiento del río Caroní; aquellos son los más crueles, que infestan los pueblos de las Misiones del Orinoco, y a quienes llaman también Galibis, y estos, de genio más pacífico, a quienes empezaron a reducir los regulares de la extinguida Compañía en $1738 .^{* * * * * * * *}$

Los Caribes llaman Caribana la tierra que habitan. Los antiguos historiadores llamaban también por antonomasia Caribes a todos los indios antropófagos que se hallaban en

\footnotetext{
* Herrera. Decad. I. Lib. 6. Cap. 10.

******** Serefiere a los padres jesuitas expulsados de sus territorios por Carlos III.
}

América. Se distinguieron siempre las razas descendientes de Caribes por su tendencia feroz a la antropofagia.

Fuera de los lobos, algunos peces y otros animales, los demás no se alimentan de sus semejantes, a no ser que sean impelidos por el hambre. En el hombre, por el contrario la antropofagia es instintiva, es un estado económico anterior a la protección individual, un periodo ovular de las sociedades rudimentarias, de que hay rastros entre las más remotas civilizaciones. Plinio, Strabon ${ }^{* * * * * * * *}$, Porfirio ${ }^{* * * * * * * *}$ etc. demuestran que el canibalismo existía entre esclarecidos pueblos de la antigüedad. Los escitas, los judíos y los romanos se entregaban a veces a la antropofagia. Los sajonios fueron antropófagos cuando terminó la guerra de Treinta años. En Francia en 1030, se salía a caza de hombres para devorarlos; los parisienses en 1590 dieron ejemplos de canibalismo. En las Capitulares de Carlo Magno se hallan castigos impuestos a los comedores de gente. Está elevada a institución política y religiosa entre diversos pueblos la antropofagia. En la Polinesia, en Sumatra, en el África Central especialmente entre los Jagas; entre los salvajes de Brasil es también muy común el canibalismo.

Los Jumas, Parintintins, Mairunas, Miranhas y Pariquis son gentiles del valle del Amazonas de los más célebres como antropófagos, mas entre ellos solamente la venganza y el amor supremo arrastran al canibalismo una vez declarada la guerra entre dos tribus, los muertos y los prisioneros pertenecen al vencedor. Transforman los cráneos de aquellos en trompas, los huesos largos en membys bárbaros, las cabezas momificadas en trofeos, los dientes en collares; los prisioneros los engordan para comerlos. Estos indios jamás devoran a los de su misma tribu sino para darles dentro de sí un túmulo condigno de sus afectos.

Algunos de estos indios trafican los las Indias Holandesas y Francesas y participan de sus costumbres.

Eligen estos indios sus jefes por medio de asambleas generales y solamente cuando van a la guerra. En tiempos de paz, cada familia se rige a su antojo y no reconoce otra supremacía que la de la naturaleza. Tienen sin embargo, capitanes que son los principales de cada horda o tribu, y los que los conducen a la guerra bajo la dirección del jefe principal.

\section{Lengua cariba}

De esta lengua se derivan, según el P. Gumilla, conocedor profundo de los idiomas de la región del Orinoco, en donde

\footnotetext{
******** Estrabón fue un viajero griego que vivió entre el año 58 a.C y 25 d. C. Es autor de una extensa Geografía.

******** Alude a Plinio El Viejo, autor de varios escritos científicos
} 
vivió muchos años de misionero, la lengua guayana, la palenca, gúiri, guayaquiri, mapuy y cumanagota; fuera de que casi todas las lenguas indígenas de la región oriental y norte de Sur América, se encuentran raíces o radicales de la lengua caribe.

Los caribes, dice Lafitan ${ }^{* * * * * * *}$, explican los eclipses suponiendo, ya que la luna está enferma, ya que ella ha sido atacada por enemigos; ellos tratan de prender a estos últimos por medio de danzas, gritos y agitando la $\underline{\text { crecelle }}^{* * * * * * *}$ sa$\operatorname{grada}^{*}$

Los caribes, lo mismo que los pieles rojas, creen que cada hombre tiene más de un alma; las pulsaciones del corazón y de las arterias les han dado probablemente esta convicción, porque ellos miran estas pulsaciones como pruebas de vidas independientes. De ese modo explican la inconstancia del carácter.

En las mismas tribus en donde las ideas de una alma y de una vida futura están más desarrolladas, están lejos de tomar siempre la misma dirección que las nuestras.

\section{[F r] Origen del nombre caribe}

Don Carlos Calvo ${ }^{* * * * * * * *}$ halla entre los guaranis el significado de brujo, y asimila la palabra cariba a caraya, nombre dado al mono más grande de las selvas.

Descompone la palabra en cará que quiere decir habilidad, astucia, etc. y yá, ser disimulado.

Según Fernando Cardin ${ }^{* * * * * * *}$, caribe designaba entre algunos indios al santo o fetiche.

Marcgraff $^{* * * * * * * *}$ dice que ese término significa tanto al sacerdote como al poder sacerdotal, etc. etc.

\footnotetext{
******** El padre Lafitan, por su estudio de los iroqueses, es considerado como el primer gran etnólogo, aunque es posterior a Bernardino de Sahagún.

******** Palabra francesa que significa Carraca.

* Laf. T 1. p 248, 252, History of the Caribbi islands p. 272. Defons. Travels in South America, t 1, p. 127.

******** Abogado y hombre público nacido en Uruguay pero llevado a los pocos años a Buenos Aires. Como diplomático, representó a Paraguay y Argentina en Alemania, Bélgica, Francia, Gran Bretaña, Rusia y Austria. Fue uno de los fundadores del Instituto de Derecho Internacional Público de Gante. Además fue miembro de la Academia de Ciencias Morales y Políticas del Instituto de Francia y de la Real Academia de la Historia de España.

******** Se trata del presbítero, Fernando Cardín y Materón, religioso Capuchino, Cura coadjutor y Beneficiado de la Villa de Dalías (provincia de Almería, Andalucía, España), muerto durante una epidemia de cólera-morvo, el 30 de Julio de 1855.

******** Georg Markgraf o Marcgraf, naturalista y astrónomo sajón na-
}

\section{Antigüedades indígenas}

Apuntes sobre la lengua caribe, tomados

$$
\begin{gathered}
\text { por un antiguo } \\
\text { misionero del } \\
\text { Orinoco cu- } \\
\text { yo nom- } \\
\text { bre se } \\
\text { ig- } \\
\text { nora } \\
\text { por haber- } \\
\text { se perdido } \\
\text { las primeras } \\
\text { páginas del im- } \\
\text { portante manus- } \\
\text { crito de que es- } \\
\text { tas fijas haci- } \\
\text { an parte. }
\end{gathered}
$$

\section{M. J.}

Verbos $1^{\text {a }}$ Conjugación

Soy: ugui. Tu: amecre caene. Aquel: image caene. Vos: anamozu caene.

2a Yo cazo: ugui apicaene. tu: amecaene apicaque. Aquel: moje naficane. Vos: anamoru aficateque. Aquel: maramarai naficane.

Yo duermo: yonifiai, tu: emecae nonifiai. Aquel: moge nonifiai. Vos: anamoru nonifiai.

Tengo sueño: mone poro huai. Tengo mucho: yuri sehuai.

Tengo calentura: yatu nai. tu: matunaneca. Aquel: moge natunane. Vos: ana natunane.

Yo estoy: ugui nai.

cido en 1611, es considerado como el explorador más importante de Brasil en el siglo XVII. Es autor de Historia Naturalis Brasiliae.

******** Cabe señalar que ninguno de los vocablos mencionados en este vocabulario coincide o se parece a los publicados por Marcos Jiménez de la Espada en su Vocabulario de la lengua general de los indios del Putumayo y Caquetá, dados a conocer en la Revista de Archivos, Bibliotecas y Museos de Madrid en 1904. 
Yo estoy bravo: Atasirabai. Tu: Atasicamanai. Aquel: Atasicamenai. Nos. atasica ananai. Vos. atasica menatei. Aquel: vocamuru atasicanai.

Estoy borracho: Yesinemai. Tu: Mesinemai. Aquel Esinemai. Vos: Mesimatei Nos. Asia nesimaido. Mocamuru nesimane.

Yo tengo miedo: inomebai. Tu: inomemanai. Aquel: inomenai. Nos: inane ananai. Vos: inane camanatei. Aquel: mocamuru inomenai.

\section{D. M}

Pronombres, nombres y verbos de la lengua caribe.

\section{Pronombre}

Yo: ugui. Tu: emeere. Aquel: moge. Nos: Ina. Vos: anamoru. Aquellos: mocamoru.

El dativo es como el nominativo pospuesta la partícula a: ya: //a. mi: ugui ia.

El ablativo con la pos porción mare que significa con de comp. o la pos porción que de con instrumental. Conmigo: ugui mare, ibasa que.

Nombres, sustantivos y adjetivos

Nominativo: Guiini: Hombre. Genitivo. Gui ini. Dativo. Guini ya Vocativo: Guiini. Ablativo: Guiini mare. Pl. Guiyamo. \&a.

Guanin, mujer. Pl. Naozamo. Nota. La Z has de pronunciar como valenciano. Mi mujer dicen: Viti.

Bueno, buena, bueno. Malo mala malo

Cure, Cure, Cure Nepiosa

Relativos

Encé: el que mira.

Posesivos

Mio: ye. Tuyo: E. Suyo: Eninguirisi Nuestros: Anginguiriri Vuestros: anamoru inguiriri. De aquel: mocamuru inguiriri.

Casa: mina, quitche, cuai.

Bara: cheve Aytinai, guacurima, Pucata abotari.

Estantillos: mina ejuru.

Bejuco: niminate.

Olla: arina

Plato: guajija

Tiesto: erijo

Chinchorro: iteti

Hacha o tiradera: Firehuare

Arco: hurraja

Flecha: Huirajariri

\author{
Estudios Etnológicos de Colombia \\ Indios Chocoes \\ CH
}

Indios Chocoes

"Habitan el las provincias de Antioquia que llaman equinocciales; imitan en las trazas y traición (sic) [tradición] a los chimilas, aunque en las armas se diferencian, porque usan dardos de una braza. Son dilatadísimas y ricas estas provincias de oro, y aunque se han hecho muchas entradas en ellas por diferentes capitanes con gran copia de gente, y fundándose algunas ciudades, las han asolado los indios lastimosamente, y de ordinario han perecido a sus manos los capitanes más valerosos, como lo fueron Martín Bueno, Pereira y don Alejo de Andrada, que perdió la empresa con muerte irreparable de toda su gente, de que se hallan con tanta soberbia que no excusan de venir a las manos con los españoles sin ventajas de ardides. No hay en todas ellas pueblo alguno reducido a nuestra santa fe, ni esperanza de que se reduzcan". (Piedrahita).

\section{Diccionario etnológico de Colombia. Indios Caparras}

C

\section{Indios Caparras $^{* * * * * * * *}$}

"La provincia de Caparra, dice Cieza de León* está 12 leguas de la ciudad de Cartago, asentada en unas sierras muy ásperas rasas, sin haber en ellas montaña más de la cordillera de los Andes, que pasa por encima."

Refiere el mismo autor que la raza de esta nacionalidad era robusta, hombres altos y de buen parecer con el rostro más alargado que los otros indios, y las mujeres también altas y fornidas.

Sus casas eran bajas y cubiertas con palma, y algunos de sus señores, bastante grandes. Dentro de estas, y en grandes bóvedas o cuevas construidas a propósito, enterraban los cadáveres de sus difuntos parientes, a los cuales acompañaban también a la tumba sus mujeres, sus armas, útiles de casa \& \&.

\footnotetext{
******** Resulta claro que el fraile etnólogo no estuvo en esta región y por ello, para su obra incluye, entre comillas, el texto de Lucas Fernández de Piedrahita.

******** Como en el caso anterior, el autor cita a Cieza de Leon, por no haber realizado observaciones directas en la región habitada por los indígenas caparras.

* $\quad$ La Chronica del Perú. Part. I, Cap. XXIII.
} 
Cuando algunos de estos salvajes se sentía enfermo, los médicos, que a la vez eran sacerdotes y se decían tener relaciones y hablar con sus dioses, procedían a hacer grandes sacrificios, hasta que se mejoraba o moría el enfermo.

Eran muy dados a la borrachera, y tan viciosos en tomar chicha que, según Cieza de León "se bebe un indio de una asentada una arroba y más, no de un golpe, sino de muchas veces, y teniendo el vientre lleno de este brebaje, provocan a vómito, y lanzan lo que quieren, y muchos tienen con la una mano la vasija con que están bebiendo, y con la otra el miembro con que orinan." En cambio, para la comida eran sobrios, lo cual dependía, sin duda, del mismo vicio.

Al tiempo de la conquista su principal soberano era Irrua, cacique que en otro tiempo había gobernado en un valle grande y poblado que se extiende entre las provincias de Carrapa y Quimbaya, pero que, a consecuencia de las continuas guerras que tienen que sostener con los habitantes de esta última, se vio precisado a abandonar su patria, y entró mañosamente en la de Carrapa, y como tirano y poderoso la dominaba casi toda.

En su territorio hay muchas minas de oro que entonces ellos explotaban, y fabricaban bellísimos vasos y piezas de este metal, que después se han encontrado en sus sepulturas y de que se servían para los usos domésticos y para beber la chicha de maíz.

Si los señores morían sin hijos entraba a gobernar la principal de sus mujeres, y muerta ésta, heredaba la corona el sobrino del muerto, como entre los chibchas, pobladores del valle de Bogotá; pero siempre que fuera hijo de una hermana, pues de otra manera se desconfiaba respecto a la nobleza de su sangre.

No tenían templos ni lugar alguno de adoración, pero sus agoreros se jactaban de hablar con los seres sobrenaturales en quienes crían.

Los nobles se casaban con sus sobrinas frecuentemente, $y$ algunas veces hasta con sus hermanas, y practicaban la poligamia.

En la guerra eran feroces, y como los demás pobladores de esas regiones, antropófagos. Marchaban a la pelea ricamente adornados con coronas y brazaletes de oro, y llevaban al frente banderas de mucho color. Cieza de León dice: Yo ví una que dieron en presente al capitán Jorge Robledo, la primera vez que entramos con él en su provincia, que pesó 3000 $\mathrm{y}$ tantos pesos, y un vaso de oro también le dieron que valió 290, y otras dos cargas de este metal en joyas de muchas maneras; la bandera era una manta larga y angosta puesta en una vara llena de unas piezas de oro pequeñas, a manera de estrellas, y otras con tallo redondo".
Eran sus vecinos los Quimbayas, en cuyo territorio se fundó a la ciudad de Cartago.

\section{Diccionario Etnológico de Colombia Indios Catíos}

C

Datos sobre los indios Catios

Esta nación, una de las más notables que al tiempo de la conquista habitaban lo que es hoy el Estado de Antioquia, demoraba hacia la región occidental del río Cauca, y se componía de varias parcialidades agricultoras y bastante adelantadas en civilización.

El padre Simón ${ }^{* * * * * * * *}$ dice sobre estos indios lo siguiente:

"Eran gente vestida y de más despabilado entendimiento; escribían sus historias en jeroglíficos pintados en mantas. Usaban de peso y medida. No usaban veneno en sus flechas y dardos. Querían mucho a sus hijos y mujeres, que eran más blancas que ellos y de buen parecer, y se adornaban con arracados y otras joyas de oro. No tenían santuarios, adoraban las estrellas y tenían confusa idea del diluvio. Creían en un Dios, en la inmortalidad del alma, algunos en la metempsicosis. Sus alimentos eran raíces nutritivas, pero sus tierras eran estériles para el maíz de que hacían sus bebidas."

La provincia de los Culimas fue conquistada por el capitán don Lope de Orvico, don Antonio Toledo y don Gutiérrez de Ovalle, siendo entonces cacique "Ferama", general de los ejércitos de los indios "Murca" y su oráculo "Parripari". Fue fundada primeramente La Palma por Toledo en el sitio de "Manipi" y 3 años después trasladada al actual sitio por Gutiérrez de Ovalle con el nombre de Nuestra Señora de la Palma de la Ronda.

\section{Diccionario Etnológico de Colombia Indios Coconucos}

\section{C}

Datos sobre los indios Coconucos.

La antigua Provincia de Popayán estaba habitada por los indios algo civilizados Coconucos, Polindaras y Guambías,

******** Alude a Fray Pedro Simón y a sus Noticias Historiales de las Conquistas de Tierra Firme en las Indias Occidentales.

* Alcedo dice: Cucunuco. Montaña de la provincia y gobierno de Popayán, a levante, que siempre está cubierta de nieve; nace de ella el río Puracé y el de La Plata. Toma el nombre de una nación de indios, que la habitaba, de que ya no han quedado más que unos pocos, reducidos a la fe. Está en 2 grados 27 minutos de latitud boreal. 
pero entre estas tres tribus sobresalía la de los primeros por ser más civilizada, y ejercer en cierto modo algún dominio sobre sus vecinas.*

Vivían los coconucos al oeste del punto donde hoy existe la ciudad de Popayán y su raza se conserva hasta la fecha casi en estado de completa pureza; una de sus principales poblaciones era la de Puben, nombre primitivo que daban a la mencionada capital. El idioma de estos indios se conserva también en nuestros días, y lo usan entre sí, valiéndose des castellano cuando necesitan entrar en negociaciones con los pobladores de las ciudades a donde salen. En este idioma está puesto en único verso en lengua india que se conserva entre nosotros; lo traen, el general Mosquera en su "Geografía de los Estados Unidos de Colombia" y el señor José María Vergara y Vergara en su "Historia de la Literatura en Nueva Granada"; fue hecho indudablemente después de la Conquista y demuestra que su autor o su pueblo, podrían haber hecho composiciones de mérito, y dignas de ser conservadas; este verso lo cantan todavía hoy los coconucos como canción, la cual puede muy bien inferirse que no es más que el triste recuerdo de la conquista que les sometió y de los tiempos en que empezaba a enseñarse la religión cristiana. Sabido es que los españoles ponían en la cima de los montes o cerros una cruz, y esta costumbre la han continuado los habitantes de los campos. La canción dice así:

\section{Surubu loma \\ Nevin va \\ Canan cruz \\ Nigua gra}

Cuya traducción es la siguiente:

Subí a una altura,
Allí me senté,
Encontré una cruz,
Me puse a llorar.

Como en su idioma no existe la palabra cruz, el indio adoptó la castellana, y por un cerro ponen loma, porque no tienen como expresar mejor su idea, pero el pensamiento se puede traducir así: "Allá en la altura, donde está la cruz, me siento a llorar mi desgracia", y efectivamente los indígenas que saben castellano convienen en que eso es lo que ellos quieren decir con esas palabras de su lengua.

El sitio principal de residencia de los coconucos era el pintoresco valle de Coconuco que todavía conserva esa denominación, y en el que existe también el pueblo del mismo nombre, a cuyas inmediaciones hay aguas termales tibias y calientes. Por dicho valle va actualmente el camino que conduce a las altas explanadas de Paletará y nevados llamados igualmente de los Coconucos, de donde los descendientes de los primitivos indígenas sacan semanalmente nieve para llevar a Popayán.

Estos descendientes, que como hemos dicho, conservan todavía puro el idioma de sus progenitores, conservan también en sus facciones el tipo de los antiguos indígenas de Coconuco.

Su estatura es pequeña, y su constitución generalmente es robusta. El color de estos indios es bronceado, y frecuentemente muy moreno; la boca grande, los labios gruesos y el inferior mucho más pronunciado que el superior, los pómulos algo salientes, nariz arqueada, pelo negro y muy lacio y mirada triste y expresiva a veces.

Marchan casi siempre cargados con enormes fardos de sus víveres o de nieve; son muy esforzados, y como los guajiros gustan mucho de la coca ${ }^{* * * * * * * *}$, que van mascando constantemente mezclada con cal, y tienen grandes campos sembrados de esta planta.

Si la mirada de estos indios fuera más viva y tuviera más altanería, su parecido con los pieles rojas de los Estados Unidos sería completo, en la parte física. En la P. 2 de nuestro Atlas $^{* * * * * * * *}$ se encuentra publicado un diseño del tipo de los coconucos.

Usan estos indios en el invierno unas capas fabricadas de fique y perfectamente cubiertas de paja larga y tupida que preserva por completo del agua. Las mujeres reemplazan las naguas por medio de una tira de bayeta que se envuelven a la cintura, y que aprietan por medio de una faja de pita con bonitas labores de color, que ellas mismas fabrican.

La montaña de Coconuco, de donde nace el río Puracé y el de la Plata, toma el nombre de la nación que la habita.

Vida nómade (Para los chiricoas y ca $\mathrm{c}^{\mathrm{a}}$ )

El hombre primitivo, el que no tenía por armas y por útiles sino la piedra tallada, vivía casi exclusivamente del producto de la caza. Como los salvajes de nuestros días, tenía necesidad de grandes espacios para asegurar su subsistencia. Además, le era necesario cambiar frecuentemente de territorio para seguir en sus emigraciones a los animales, para buscar comarcas en que la caza fuera más abundante y menos feroz que en los parajes de tiempos atrás habitados. Su vida era forzosamente nómade. Su instalación sumaria le costaba poco trabajo y la dejaba sin dolor; toda su fortuna consistía

\footnotetext{
******** Se refiere a la costumbre de consumir hojas de coca (Erythroxylon coca). El mambe es la mezcla de las hojas secas y tostadas con cal.

******** Infortunadamente este Atlas, donde están ilustrados los indígenas tratados, permanece refundido.
} 
en algunos instrumentos groseros y algunas pieles de bestias. Unidos a esta necesidad de moverse por carencia de medios para hacer vida sedentaria, unidos el atractivo de los desconocido, el humor aventurero, la persecución de un ideal muy natural, un país rico en frutos y en caza, con cuya posesión, en esta vida y la otra, sueña el salvaje; así se explica cómo los primeros grupos humanos se alejaron de sus centros de origen.

\section{Galería Etnológica Colombiana Indios Chiricoas}

\section{CH}

Uno de los alimentos favoritos de estos indios, es la carne de Buios o Güios, grandes culebras o boas, lo que hace que en el verano anden en tropas trasegando lagunas y quebradas y los ríos Meta, Cravo, Guanapalo y otros. Persiguen también al armadillo que cogen sin otra diligencia que prender fuego a las sabanas en que tienen cuevas, y acá encuentran los vívares a cada paso y cavando en las madrigueras los sacan.

(Nota) Los datos de los Guajibos son aplicables a los Chiricoas.

\section{Diccionario Etnológico de Colombia Indios Conchas}

\section{C}

Indios Conchas

Los Conchas habitaban al Norte de Santa Marta y eran vecinos de los Tagangas.

\section{Diccionario Etnológico de Colombia Indios Correguajes}

\section{C}

Datos sobre los indios correguajes

Habitan los indios Correguajes entre los ríos Yarí, Caguán y Orteguasa, en el territorio del Caquetá. Andan sin vestido, pues solamente los hombres usan el fono que fabrican de corteza de maderas en forma de un cinturón, del que sale el delantal, y las mujeres casadas usan una concha de nácar pendiente por delante. Son bien formados, ágiles y buenos bogas; se dedican a la pesca y a la cacería dejando a cargo exclusivo de las mujeres el cuidado y las faenas del campo.

Su lengua es distinta de la de los Guaguas, pudiéndose decir, según Codazzi $^{* * * * * * * *}$, que es un dialecto de la de los Tamas,

\footnotetext{
******** Se trata de Agustín Codazzi, el director de la Comisión Corográfica.
}

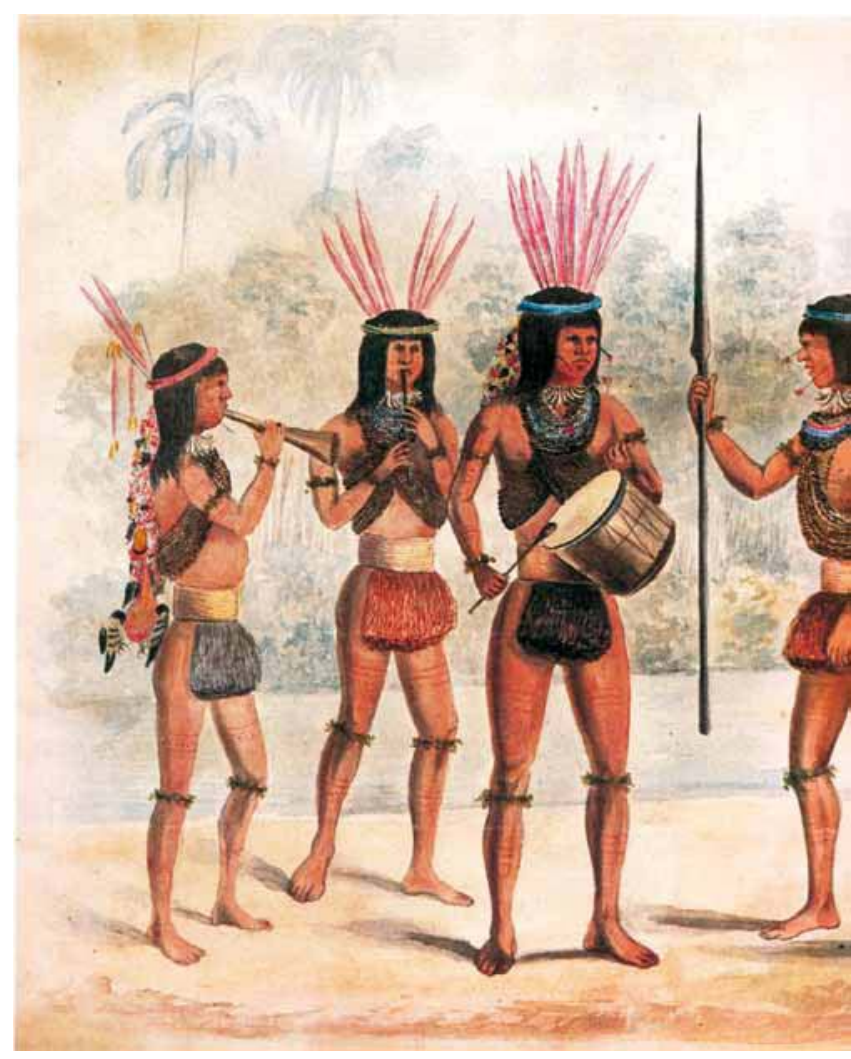

Indios coreguajes con sus adornos, Acuarela de Manuel María Paz. No. 75.

con quienes se entienden. Viven sin gobierno, y cada familia, compuesta de 50 o 60 personas, se reúne en una o dos casas, a las orillas de los ríos o cerca de las lagunas. Extraen bastante cera blanca, con cuyo producto se procuran herramientas, chaquiras, \&. Hombres y mujeres acostumbran quitarse las cejas haciendo uso para eso de una goma de un árbol, la cual al adherirse a estas partes, arranca los cabellos que las forman. Codazzi calculó su número en 1000 .

Entre las láminas hechas por la Comisión Corográfica, y que existen en la Biblioteca Nacional, se encuentra una (No. 75) que representa tipos de indios correguajes con sus adornos, y de la cual hemos tomado la que se encuentra en la $\mathrm{Pl}$. de nuestro Atlas y que da una idea de los tipos y aderezos de estos indios. También existe en la mencionada colección otra lámina, No. 97, que representa a dichos salvajes cazando con la bodoquera ${ }^{* * * * * * * *}$. Ambas láminas, a la aguada, son incorrectas, tanto en el dibujo desproporcionado y duro, como en el colorido que es falso y chillón, pero son sin embar-

******** Se refiere a dos láminas elaboradas por Manuel María Paz en julio y agosto de 1857 en territorio del Caquetá. 
go importantes por la idea que, a pesar de su imperfección dan, acerca del tipo, los vestidos, los adornos, instrumentos y costumbres de estos salvajes. En la primera, a las orillas de un caudaloso río están en el primer plano cuatro indios, uno tocando el tamborcillo, otro una especie de trompa y otro una flauta de tocar verticalmente o pífano de caña, mientras otro, con un arpón de chonta en la mano baila; todos llevan grandes collares de colmillos y de granaticos de colores, delantales cortos, cinturones de corteza, ligaduras de plantas aromáticas, capillos de plumas, llevan pendientes hasta aves enteras desecadas, diademas con plumas, y cruceros en el pecho. En el segundo plano hay tres mujeres, una de ellas con un niño en las espaldas, y un hombre. Van ellas más desnudas que ellos, pues su delantal es pequeñísimo y de forma triangular, que cubre apenas las partes genitales y sostiene atado en la cintura y por la entrepierna con cordones. Todos llevan en las orejas palillos; y el rostro, brazos y piernas están pintados de rojo.

En la segunda hay, entre un tupido bosque, un hombre que dispara una saeta por su cerbatana; el vestido es solamente

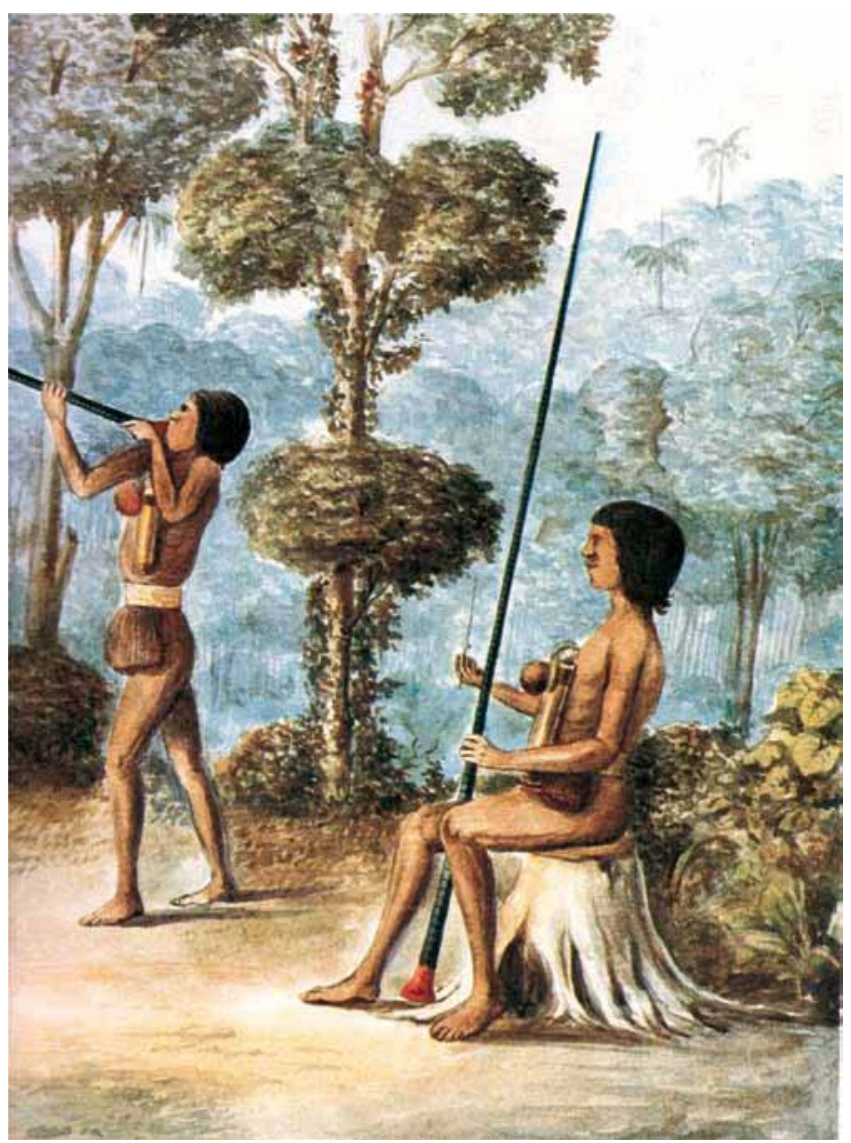

Indios coreguajes cazando con bodoquera. Acuarela de Manuel M. Paz. No, 97. un fajón y el delantal, leva como los macaguajes, pendiente el el tarrillo con las flechas, y el calabacito de veneno. Otro indio, sentado en el tronco de un árbol espera. con la cerbatana vertical, y la saeta envenenada en la mano, seguramente a que tire el otro, para hacerlo luego él.

Los correguajes usan en sus fiestas grandes adornos y siempre escogen para ellos los colores más vistosos; traen sobre la cabeza, los de rango más alto, una corona de una pulgada de ancho, hecha con las alas externas de un coleóptero verde, las cuales encajan, unas sobre otras. Por detrás pónense en esta corona, y paradas verticalmente, varias plumas grandes y de los más primorosos colores; cuélganse también de la cabeza varios pájaros disecados de los más bellos que han cogido, colgados de hilos con plumas, chaquiras y conchas de perla, y pepas silvestres de muchos matices.

El pelo lo tienen echado para atrás y lo sujetan con peines fabricados por ellos de palo y a manera de los que llamamos peines tupidos, a veces los construyen también de las fibras que dan las hojas de las palmas; hemos visto en el Museo Nacional de Bogotá, uno de estos peines, con adornos muy curiosos.

Sobre las orejas tienen palillos que proyectan a los lados de la cara y en cuyo extremo hay en cada uno un cordel con bellísimas y pequeñas plumas. Al cuello tienen sartales de los colmillos de tigres y otros animales feroces que ellos mismos han de haber matado, y en lo cual puede bien conocerse el rango y valor del que los trae.

Píntanse la frente y las mejillas con caprichosas rayas rojas, lo mismo que los brazos y las piernas en los cuales se forman círculos de puntos y de rayas a manera de fajas que os rodean. Abajo de las rodillas se atan también lo mismo que en los brazos y las muñecas, en sus días de gala, con ramas de bejucos, cuerdas con hojas verdes y olorosas, las cuales forman un raro contraste sobre la piel rojiza de los salvajes y las listas rojas que los circundan.

Sus armas son la flecha y la macana, hechas del palo negro y duro que también llaman macana y púas de la misma madera, en forma de lanzones, y que construyen en agudísima punta.

Curioso es ver a los correguajes en sus días festivos danzar al son de sus tambores, pífanos y trompas, haciendo sonar en confuso traqueteo todos sus cascabeles y caracoles.

Terciados sobre los hombros, y pasándoles por debajo de los brazos, llevan sartales de piedrezuelas y cordones de colores, y sobre el pecho les cuelgan anchos collares azules y rojos, formados con cuentas de vidrio y cuando no las tienen, las 
fabrican de semillas duras y relucientes, a lo cual añaden sartas de dientes de tigre, leones y monos y de frutas olorosas con que se cruzan el pecho y parte del cuerpo, completando los adornos, como ya dijimos, con brazaletes y ajorcas de hojas muy aromáticas que mantienen y renuevan cuidadosamente.

Los hombres llevan un fuerte y ancho cinturón de corteza de árbol que les ciñe el vientre y sujeta un pequeño delantal, mientras que las mujeres casadas se contentan con una concha de nácar, más por ostentación y distintivo de su estado, dice Codazzi, que por cubrir lo que las solteras dejan al aire libre.

Ponen estos indios mucho cuidado, y manifiestan ingenio en la fabricación de las bodoqueras, de dos y hasta tres metros de largo, hechas del tallo delgado de la palma llamada macana, perfectamente pulimentadas por dentro y aforradas por fuera con un compacto tejido de cuerda encerada. Tejen redes para la pesca, poniéndoles pedrezuelas en vez de plomo, de que carecen.

Sus fiestas consisten en bailes y borracheras, ya con ocasión de un casamiento, ya por el cumpleaños de un muerto, ora porque los adivinos prometen una buena cacería de puercos, ora después de ella o de una cacería hecha en común. No hay festín, no hay danza, no hay entierro en el que la chicha no haga el primer papel; sus danzas, monótonas al principio, se hacen bulliciosas con el licor; hombres y mujeres se exaltan, cantan y gritan hasta más no poder, y estas diversiones salvajes, que hacen su existencia en extremo feliz, se celebran al son de una especie de arpa, pitos, zampoñas, tambores y cornetas de barro cocido.

No se encuentra entre estos salvajes vestigio alguno de adoración ni culto, pues no se les conocen adoratorios ni ídolos, ni se les ha visto demostración alguna de culto, ni los casamientos tienen allí nada de religioso; los médicos, que también son sus adivinos, son muy venerados por estos bárbaros; son estos unos charlatanes y embusteros que se dicen conocedores del porvenir, y que son mirados con un respeto que casi puede llamarse supersticioso.

Sus caseríos se componen de miserables cabañas de techo cónico y sin más muebles que algunas olas y cántaros para la chicha.

Como dijimos al principio, una vez que los hombres derriban los árboles y preparan los terrenos para la siembra, cada año, dejan exclusivamente al cuidado de sus mujeres la dicha siembra y demás faenas del campo, porque tienen la preocupación de que así como ellas saben parir, deben también saber sembrar mejor para que la tierra pueda producir las semillas o raíces que se han depositado en su seno.
Cultivan la yuca, el plátano, las piñas, y unas pocas matas de caña y de maíz. En el verano extraen cera blanca para hacer sus pagos, pero a causa de su habitual pereza y vanidad, las empresas de estos salvajes avanzan poco, pues la mayor parte del día la pasan, como los afeminados salivas, tendidos en la hamaca, recreándose en el espejo, y pintándose el cuerpo con el achiote y la jagua. Y solo cuando se ven muy impedidos por la necesidad, salen a buscar en la pesquería y la caza un alimento que les dura pocos días. Tienen para ello embarcaciones más o menos grandes, y puertos señalados en los ríos que atraviesan su territorio. Pero sus canoas son sumamente incómodas, lo que agregado a la rapidez de aquellos ríos anchurosos de las soledades tan salvajes como sus habitantes, hace que sea insoportable la navegación para las personas que a ella no están acostumbradas.

Cuando se enferma algún indio, esperan tranquilamente en la hamaca la hora de la muerte; llegada esta, la mujer, hijos y parientes del difunto, pintan cuidadosamente todo el cuerpo, y presididos de una vieja, que marcha tocando un mate, dan vuelta al rededor del difunto, ostentando los hombres cucharas, macanas, arcos de flechas, bodoqueras y cuantas armas tienen. Durante esta ceremonia cantan y lloran, arrojando los trastos del difunto a la candela; si el difunto dejó algunos animales, los matan, y si algunos sembrados, los arrancan. En seguida lo llevan en la hamaca en que murió, al monte, y allí lo dejan colgado para que se lo coman los animales y queden limpios los huesos. Cuatro o cinco días después van a recogerlos, y la persona más allegada trae la cabeza a las espaldas, colgada de una cuerda, mientras llegan con la carga fúnebre preparan una hoguera de caimito verde, donde arrojan los huesos y guardan su ceniza para pintarse con ella, teniendo el primer derecho los parientes. Esta ceremonia sirve para olvidar la memoria del que murió un año antes, y así concluyen los tres días de esta fiesta, en los cuales han agotado una gran cantidad de chicha y bailado sin interrupción.

En un curioso cuaderno publicado en 1855 en Popayán, por los señores José M. Vergara y Vergara y Evaristo Delgado, cuyo título es: "Los indios del Andaquí. Memorias de un viajero.” por el presbítero Manuel María Albis, Sacerdote que recorrió el Caquetá, Se encuentran noticias muy importantes sobre estos y otros indios. De allí hemos tomado algunos datos para nuestro trabajo, y el pequeño vocabulario de la lengua correguaje que a continuación insertamos:

\begin{tabular}{ll}
\multicolumn{1}{c}{$-\mathbf{A}-$} & \\
Aca, & Perdiz \\
Achi, & Hermano \\
Anameo, & Rayo \\
Anoco, & Sapallo, Aullama \\
Anzo, & Yuca \\
Aña, & gusano, culebra.
\end{tabular}




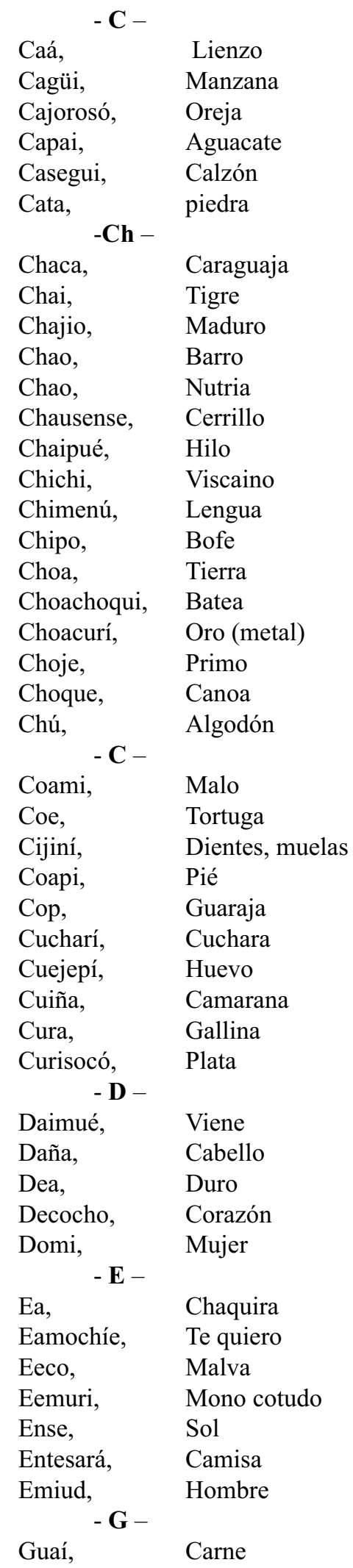

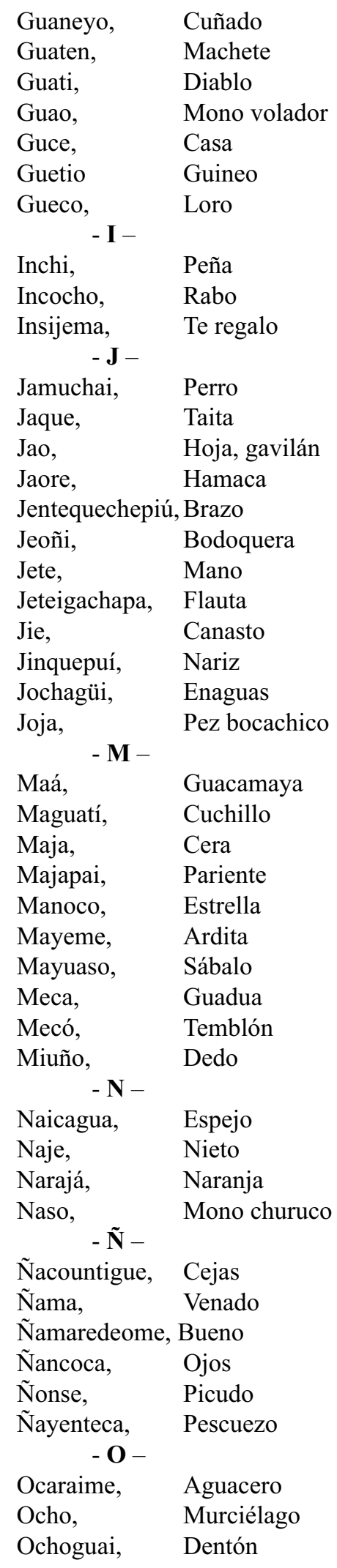




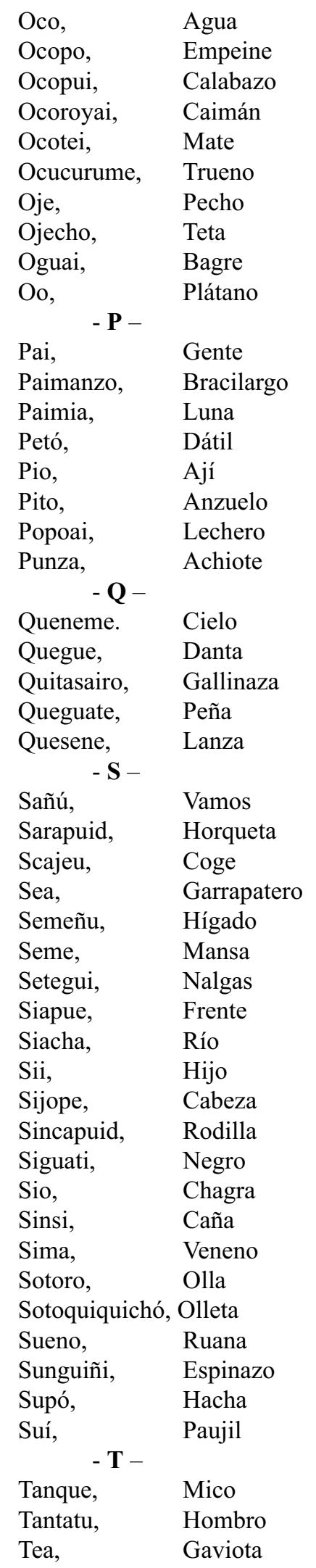

\begin{tabular}{|c|c|}
\hline eti, & vaso \\
\hline oapi, & Pierna \\
\hline Tochachai, & Tigrillo \\
\hline Tocorogua, & Codo \\
\hline Totoreagua, & Plato \\
\hline Toro, & Lagartija \\
\hline Turupí, & Mochila \\
\hline Tuiro, & Sombrero \\
\hline Tuapi, & Canilla \\
\hline Tutu, & Viento \\
\hline$-\mathbf{U}$ & $\mathrm{Sa}$ \\
\hline Uchepe, & Gorda \\
\hline Ujepui, & Papaya \\
\hline Uje, & Sardina \\
\hline nct & Tórtola \\
\hline inu, & Moc \\
\hline
\end{tabular}

\section{Diccionario Etnológico de Colombia Indios Cunas}

\section{C}

Datos sobre los indios cunas.

Hacia la desembocadura del río Atrato, y en la costa y la serranía que se hallan sitiadas al oriente del Golfo de Urabá, habitaban antiguamente y habitan aun los indios Cunas, los cuales van en sus correrías hasta las márgenes del río Carepa. Encuentraseles también hacia la parte occidental de dicho golfo, en donde estuvo situada la Antigua del Darién, y en casi todos los bosques de la vecina cordillera.

Los antiguos vecinos de esta tribu numerosa y compuesta de varias parcialidades, eran los Mandingas y Anachunas que vivían desde la costa de San Blas hasta el golfo de Urabá en las costas del Darién y en toda la antigua provincia de este nombre; hoy parece que de esas nacionalidades no quedan descendientes, y que solamente los indomables caimanes acompañan a los cunas en sus bosques y comparten con ellos y las fieras el imperio de esas vírgenes soledades. Allí se han conservado independientes de todo poder extraño; trafican con los extranjeros, mas sin que ese comercio sea causa para que ellos abandonen las costumbres ni olviden las tradiciones de sus antepasados.

Las poblaciones cunas son muy numerosas, pero todas están unidas entre sí por alianzas ofensivas y defensivas. Se rigen por un cacique o jefe, que ordena los trabajos públicos y comunes y a quien dan todos parte de sus ocupaciones; empero, parece que su mando es solamente temporal y que es electivo. 
Tienen además médicos y adivinos que hacen también de sacerdotes. Estos son por lo común ancianos, y en su derredor se juntan todos los días los indios para oír la tradición de los sucesos pasados y las pasadas guerras, lo mismo que las proezas militares de sus mayores. Es de esta manera como los cunas conservan su historia, la cual, grabada de este modo profundamente en la memoria de todos, les es más provechosa y conocida, y contribuye en gran manera a conservar en ellos el espíritu de libertad e independencia que tanto amaron sus mayores.

Estos augures, que como ya dijimos, son también los médicos, pasaban antiguamente, en el desempeño de esta última misión, por pruebas terribles. Los maliciosos indígenas tenían establecido que, cuando uno de sus jefes u hombres principales se enfermaba, el médico tenía el deber de tomar la mitad de todos los medicamentos que prescribía; en el caso de morir el paciente, introducíanle en la boca un polvo compuesto de fragmentos de sus uñas, de un puñado de su cabello, y de una misteriosa planta, conocida solamente por ellos, y preguntábanle si el médico había tomado exactamente los remedios. Tenían sus señales especiales para conocer cuando era positiva la respuesta y cuando no lo era, y en este último caso, vigilábase al falso Esculapio durante los funerales, y terminados estos, los parientes del difunto lo apaleaban, sacábanle los ojos y le mutilaban horrorosamente.

Son estos indios de regular estatura, cuerpo bien formado y robusto, frente alta, ojos algo oblicuos, nariz saliente, boca grande, labios gruesos, cara ancha, cabello muy negro y liso, piel cobriza y mirada expresiva.

Andan por el campo, desnudos, pero al entrar a los poblados se visten algo, para lo cual llevan consigo su sencillo traje en un cesto. Cuando están en los bosques se limitan a cubrirse el cuerpo con pintura de base de orellana o de chica, que se obtiene de las bignonias y produce una fécula de color rojo, que es la que los indígenas utilizan como tinte. El árbol llamado chica, es de hojas lustrosas de color carmesí. Puestas estas a cocer al fuego, despiden su color tan espeso, que dejándolo reposar algunos días, se halla una masa roja que era la que los indígenas empleaban y aun emplean para pintarse ellos y pintar sus mantas.

Los antiguos cunas, como casi la totalidad de las tribus indígenas americanas, usaban la bodoquera o cerbatana en sus cacerías, además de la flecha. El veneno que a sus dardos aplicaban, de una ranilla que es muy abundante en toda la región del Chocó. El doctor Saffray, que tuvo ocasión de examinar científica y detenidamente este animal, dice que es la especie Phyllobates melanorrhinus, cuyo veneno solo ejerce su acción sobre los órganos locomotores, y mata, como el curare, por asfixia. Es este gekco, de unas tres pulgadas de largo, dorso amarillo con manchas rojas, los ojos grandes y negros, y una mancha del mismo color en la nariz. Los indios conservan esta rana, o una variedad de vientre negro, en nudos de bambú, de donde la sacan cuando la necesitan, y atándola a una rama verde, la exponen a un fuego lento, en donde se cubre de un moho blanquecino, y luego de un aceite amarillo, que recogen frotando la piel de la víctima; muchas veces las ranas sobreviven a esta terrible operación, y nuevamente guardadas les sirven para otras ocasiones.

Los egipcios conocieron también una especie venenosa de gekco, del cual se servían para envenenar también sus dardos, circunstancia que de paso anotamos, por ser tantas las semejanzas que contribuyen a hacer creer que, entre las colonias que poblaron la América, vino precisamente una emigración egipcia. (Véase "La Patria", nos. 20 y sigs. Primera memoria sobre las probabilidades de la venida de una emigración egipcia a América muchos siglos antes de la Conquista.).

Actualmente los cunas que sostienen ya algún comercio con las poblaciones de las márgenes del Atrato, han cambiado sus rústicas armas por las de fuego que consiguen en cambio de conchas y productos de sus vírgenes bosques. Cumplidores exactos de sus promesas y contratos, y teniendo además la gran ventaja de su situación sobre la costa del golfo de Urabá, mantienen igualmente con los navegantes extranjeros, y aprenden a bordo de sus buques la marina costanera.

Estiman muchísimo las escopetas inglesas principalmente, y a cambio de ellas, de pólvora, municiones, ropa, herramientas, espejos, cuantas de vidrio y aguardiente, dan sus maderas, su caucho y demás resinas, el carey que obtienen en abundancia por medio de la constante pesca de la tortuga que lo produce, los cocos, la tagua o marfil vegetal, el maíz y todas sus otras producciones.

Activos en sus especulaciones, pasan estos indios de las cabeceras de los ríos Tarena, Caqui y Anquía al Tapalisa o Paya, tributario del Tuira que cae al Chucunaque. Por el río Quía pasan al Neque, que cae al Tuira, y por el el Truandó van al Juradó, sobre el Pacífico, en el estado de Panamá, donde hay muchos cunas que fabrican embarcaciones, las que llevan a vender a las poblaciones costaneras.

La caza y la pesca suministran a estos indígenas, junto con el producto de sus siembras, lo necesario para vivir. Dejan a la manera de los chocoes, las cosechas fáciles al cuidado de sus mujeres, tomando ellos a su cargo los desmontes y trabajos que requieren un esfuerzo mayor.

Los cunas han sido llamados también cunacunas, lo cual ha dado lugar a que se crea por muchos, que estas son dos tribus 
diferentes, pero estos no eran sino dos nombres diferentes aplicados a una misma nación; hemos hallado la confirmación de esto en un documento manuscrito e inédito que existe en la Biblioteca Nacional, y el cual prueba claramente lo que dejamos dicho. Es este, el contenido en el volumen II de manuscritos de la Sección "Pineda" y en el cual aparece una carta dirigida al rey de España en el año 1787 por varios miembros del Cabildo de la ciudad de Cali, pidiendo se adjudique la misión de los Cunas o Cunacunas, "que se sitúan inmediatos a la provincia del Citará del gobierno del Chocó," a los religiosos del Convento de San Francisco de Cali, por haberse acabado, a consecuencia de las viruelas, la que tenían a su cargo estos religiosos en la provincia del Raposo, y quedar muy distante de ellas la de Caquetá, que en reemplazo de esta se les había adjudicado.

Los cunas fueron en otro tiempo temibles por su ferocidad y continuos ataques, tanto para los que navegaban las aguas del Atrato, como para los habitantes de las poblaciones situadas en las cercanías de este río. El pueblo de Pavarandó, por ejemplo, fue completamente destruido y saqueado en los últimos años del siglo pasado, motivo por el cual lo abandonaron sus moradores, lo mismo que al de Urabá. Según refería un anciano que vivía todavía en 1853, y que fue de los pocos que se escaparon, se sabe que motivó este suceso, el haber azotado y expulsado el alcalde de Paravandó a unos indios; este corrió y dio el aviso a sus compañeros de tribu, quienes un día al amanecer atacaron y destruyeron por completo el pueblo, y después, cuando se estableció una aduana en la isla del muerto, hacia las bocas del Atrato, todavía manifestaban su rencor molestando a los empleados de dicha oficina, y haciéndoles comprar por temor, cantidades dobles y aun triples de víveres para su manutención.

Todavía, en la actualidad, después de haber sido ocupado el territorio de los cunas por tantas personas, y en tan repetidas ocasiones, les causa desagrado el que algún extranjero se establezca en él, mas debe tenerse en cuenta que ha dado origen a su odio, la conducta aleve de los aventureros, quienes en diversas épocas se han apoderado violentamente de los esfuerzos industriales de los indígenas, y han violado todos sus derechos.

El lenguaje cuna, que estos indígenas hablan, ha sido hasta la fecha poco estudiado. Sin embargo, hemos visto la gramática y vocabulario de dicho idioma que el señor doctor José Vicente Uribe, que habitó algún tiempo entre estos indios, ha escrito en unión del muy ilustrado y distinguido literato, señor Dn. José María Quijano Otero. Esta obra no será ya simplemente un estudio comparativo, como las que los antiguos misioneros escribieron en los primeros tiempos de la Conquista y colonización, sino que también tendrá su parte verdaderamente filosófica; ella vendrá a dar una página más, con las Celedón y Uricoechea, a la filosofía colombiana, y contribuirá, sin duda, a demostrar la unidad de raíces de todas las lenguas indias derivadas según lo creen autoridades literarias de primer orden, de una lengua madre única, a pesar de las grandes diferencias que a primera vista se notan entre unas y otras, diferencias producidas, según lo opinan Humboldt y otros sabios, del grande aislamiento en que vivían casi todas las nacionalidades americanas, las cuales, bajo la influencia de climas diferentes y situaciones topográficas distintas, tuvieron con el tiempo diversidad de idiomas, de costumbres y de religiones. La lengua cuna parece que es inmediatamente derivada de la caribe, pues es casi un hecho demostrado hoy, que hubo en épocas lejanas una comunicación entre las diversas secciones del Continente Suramericano, y que las naciones guaraní y quechua ejercieron una gran influencia sobre los pueblos del norte. La nación Caribe, desde el Amazonas, el Ríonegro y el Orinoco, hasta las Antillas, participó de la civilización de esas dos naciones. La topografía de la región oriental, con sus inmensas llanuras, en donde el Orinoco y el Amazonas se dan un solitario abrazo, facilitó por medio de ellas y de sus caudalosos ríos, la emigración que vino del sur, dando lugar a nuevas nacionalidades y a la importación de vocablos que más o menos adulterados han llegado hasta nosotros sin perder su tipo y origen primitivos. En este caso se halan las sílabas hua y gua, de origen guaraní $\mathrm{y}$ quechua respectivamente, $\mathrm{y}$ aceptadas y propagadas por los caribes, las radicales del agua, para, y quiare, uni, y otras raíces de las cuales ha quedado el sello en multitud de nombres propios desde Paraguay (río de las coronas según Ruiz Montoya, y gran río, según otros), hasta Panamá, corrupción de Paramá (agua abundante en peces).

Contribuye a comprobar esta creencia, además de las razones filológicas, el haberse conservado entre los cunas, los taironas, los guajiros y demás habitantes indígenas de la costa Atlántica, las costumbres bélicas y el valor indomable de los feroces caribes, valor que les ha hecho conservar hasta hoy su independencia.

En el Chocó se conservan todavía una gran cantidad de palabras y nombres geográficos indígenas. Así, por ejemplo, desde la misma palabra chocó, todas las acabadas en ó aguda son de origen cuna; la terminación do quiere decir río en este idioma; por ejemplo Murindó (nombre que aun llevan un río y un pueblo), significa río del oro (uuin, oro, dó, río).

Probable es que el nombre Atrato sea una corrupción de $\underline{\text { Atradó}}$. Significando río la terminación dó, ella tiene que ser mas abundante en los nombres indígenas de estos y así la hallamos en : Amburibidó, afluente del Atrato, Aporó, Apurimiandó, Buchadó, Baudó, Corredó, Chintadó, Chichadó, Chigiridó, Chaquinandó, Catugadó, Chuigó, Curundó, Cardó, Chandó, Chiguarrodó, Capurandó, Cuchadó, Dogadó, 
Dopordó, Dotenedó, Docoró, Doroputó, Guaitadó, Humadó, Juradó, Merendó, Mongudó, Ogadó, Urodó, Nagaradó, Partadó, Taridó, Viguadó, Taparó, Tundó, Tumbutumbudó, Tutunendó, Saudó, Pató y más de cien más.

Posteriormente se han fundado poblaciones a orillas de esos ríos, y ellas han tomado los nombres de estos; también es probable que varios pueblos cuyos nombres tiene dicha terminación, existieran desde el tiempo de los primitivos indígenas con las mismas denominaciones de hoy; entre nombres de poblaciones tenemos los siguientes: Antadó, Baudó, Bagadó, Lloró, Murindó, Quibdó, Tadó \&. En cuanto a los demás nombres geográficos, puede atribuírseles el mismo origen, así, la laguna Truandó, es formada por el río de este nombre; igual cosa sucede con la laguna Pacurucundó. La misma cosa puede decirse de los cerros y montañas, como Iró, Tengadó, Yarapetó, Baudó \&.

Es muy notable, y contribuye a corroborar lo dicho ya atrás sobre unidad de origen de las lenguas americanas, el que se encuentren algunas raíces comunes entre las lenguas de pueblos tan separados como lo estaban los cunas y los chibchas, y sin embargo, estas raíces comunes existen; así por ejemplo Nemocón, lamento del león entre los chibchas significa la misma cosa entre los cunas con solo el cambio del con en cun y quirá que entre aquellos era asiento (v.g. Zipaquirá, asiento del Zipa), también lo es entre estos.

\section{Agradecimientos}

Expreso mi sincero agradecimiento al reverendo Padre Luis Carlos Mantilla Ruiz O.F.M., quien me facilitó el manuscrito objeto de este trabajo.

Recibido: 22 de marzo de 2013

Aceptado para su publicación: 4 de junio de 2013 